\title{
Matrix metalloproteinase-2 (MMP-2) is associated with survival in breast carcinoma
}

\author{
A Talvensaari-Mattila', P Pääkkö ${ }^{2}$ and T Turpeenniemi-Hujanen ${ }^{*, 3}$ \\ 'Department of Obstetrics and Gynecology, PO Box 5000, 900 I4, University of Oulu, Oulu, Finland; ²Department of Pathology, PO Box 5000, 90014 , \\ University of Oulu, Oulu, Finland; ${ }^{3}$ Department of Oncology and Radiotherapy, PO Box 5000, 900 14, University of Oulu, Oulu, Finland
}

\begin{abstract}
Adjuvant therapy is one of the major advances in the treatment of breast carcinoma patients - but do all patients need it? New predictive markers, which are able to save breast carcinoma patients from the most toxic adjuvant therapies, are still needed. The expression of matrix metalloproteinases (MMP-2) has been previously linked to invasiveness of carcinoma cells. In this study, we explored the role of MMP-2 as a prognostic factor in breast carcinoma in a large series to be able to show the favourable effect of MMP-2 negativity in poor prognosis subgroup of hormone receptor-negative patients. The MMP-2 immunoreactive protein was evaluated from primary adenocarcinoma of the breast in 453 cases by using a specific monoclonal antibody in immunohistochemical stainings. The MMP-2 protein found in breast carcinoma tumour cells was here shown to be associated with a shortened recurrencefree survival or relative overall survival $(P=0.03)$. It was shown here that MMP-2 negativity is significantly linked to favourable prognosis in patients considered to be at risk due to their hormone receptor negativity. In the patient group presenting with a progesterone receptor-negative tumour, the survival rate of the MMP-2-positive cases was 58\% while it was 95\% in MMP-2-negative cases after 10 years of follow-up $(P=0.005)$. The present data shows for the first time that MMP-2 negativity could serve as a marker for favourable prognosis in breast carcinoma patients with a hormone receptor-negative tumour usually associated with high risk. MMP-2 is also shown to correlate to shortened survival independent of major prognostic indicators in patients with primary breast carcinoma.
\end{abstract}

British Journal of Cancer (2003) 89, I270- 1275. doi:I0.1038/sj.bjc.660I238 www.bjcancer.com

(c) 2003 Cancer Research UK

Keywords: gelatinase A; 72 kDa type IV collagenase; metastasis; invasion

Breast carcinoma is the most frequent malignancy among women in Finland as well as in other Western countries (Finnish Cancer Registry, 1995; Parkin et al, 1997). It is a pathologically and clinically heterogenous disease with variable prognosis. Breast carcinomas are potentially highly malignant tumours due to their capacity to invade locally and to metastasise. The traditional prognostic factors of breast carcinoma include the size of the primary tumour, axillary lymph node involvement, tumour grade, oestrogen or progesterone receptor status of the primary tumour and menopausal status of the patients.

Tumour invasion and metastasis are the major causes of treatment failure or death for carcinoma patients. The role of matrix metalloproteinases (MMPs) in tumour invasion and metastasis as well as in tumour angiogenesis is important. Matrix metalloproteinase-2 (MMP-2/gelatinase A/72-kDa type IV collagenase) is a member of zinc-dependent endopeptidases that degrade matrix proteins, among other type IV collagens in basement membranes (Liotta and Stetler-Stevenson, 1990; Liotta et al, 1998; Curran and Murray, 1999). The expression of MMP-2 has been strongly associated with the progression of malignancy of several types of carcinoma (D'Errico et al, 1991; Levy et al, 1991; Ellenrieder et al, 2000; Sakata et al, 2000; Giannelli et al, 2002). In

*Correspondence: Dr T Turpeenniemi-Hujanen;

E-mail: turpeenniemi.hujanen@ppshp.fi

Received 25 March 2003; revised 2 July 2003; accepted 8 July 2003 primary skin melanoma (Väisänen et al, 1998), lung carcinoma (Kodate et al, 1997), ovarian carcinoma (Davidson et al, 1999) and brain neoplasms (Jäälinoja et al, 2000), the expression of the immunoreactive protein for MMP-2 was associated with a poor prognosis. In several studies, MMP-2 has been shown to be expressed in breast carcinoma (Liotta and Stetler-Stevenson, 1990; Monteagudo et al, 1990; D’Errico et al, 1991; Davies et al, 1993; Tryggvason et al, 1993; Iwata et al, 1996; Garbett et al, 1999, 2000; Jones et al, 1999) and it has been localised in breast carcinoma cells using immunohistochemical methods (Daidone et al, 1991; Höyhtyä et al, 1994). In limited series, MMP-2 positivity is associated with unfavourable prognosis in both premenopausal and postmenopausal node-positive breast carcinoma patients (Talvensaari-Mattila et al, 1998, 1999, 2001).

This study is aimed at defining the possible favourable effect of the MMP-2 negativity in primary breast carcinoma in high-risk patient groups while confirming the MMP-2 immunoreactive protein as a prognostic factor also in node-negative breast carcinoma.

\section{MATERIALS AND METHODS}

Breast tissue samples were from the primary tumours of 453 patients operated on during the years 1981-1995 in Northern Finland. The formalin-fixed, paraffin-embedded blocks were obtained from the files of the Departments of Pathology, Oulu 
University Hospital and the Central Hospitals of Kajaani, Kemi, Kokkola and Rovaniemi. The minimum follow-up time was 60 months (range 60-150 months).

Stage, tumour size and axillary node involvement of breast carcinoma were determined according to the UICC TNM classification (Hermanek and Sobin, 1992). The tumours were classified according to the World Health Organization's International Classification of Breast Tumors (Scarff and Torloni, 1986). The ductal carcinomas were graded (I-III) by evaluating tubule formation, nuclear pleomorphism and the mitotic rate according to the criteria of Bloom and Richardson (1957).

The patients were 26-85 years of age, the median age being 52 years. Ductal infiltrating carcinoma was the most frequent histological type. In this material, the number of the node-positive cases is over-represented, 302 out of 453 patients, to increase the power to test the effect of MMP-2 negativity in advanced breast carcinoma. A small tumour sample taken during the operation was used for routine steroid receptor assays. Both oestrogen and progesterone receptor charcoal assays were performed in 334 cases. In all, 65 tumours were both oestrogen and progesterone receptor negative. Mastectomy with axillary evacuation was the primary treatment in most of the cases, one case remained inoperable.

All patients without distant metastases and with histologically positive axillary lymph nodes, regardless of the number of nodes or size of the primary tumour, received postoperative radiotherapy covering the axillary, supraclavicular and internal mammary lymph nodes and the chest wall around the mastectomy scar. Adjuvant antioestrogen therapy had been used in 138 cases, most of them with a stage II or III disease, and adjuvant cyclophosphamide-methotrexate-fluorouracil (CMF) chemotherapy in 104 cases or FEC (5-fluorouracil-epirubicin-cyclophosphamide) in 96 cases. Patients with metastatic disease (M1) were operated (except one) and local radiotherapy was given. Additionally, the patients received antioestrogen therapy (10 patients) or chemotherapy (two patients). Recurrences in patients with receptorpositive tumour were treated primarily with hormonal therapy.

\section{Immunohistochemical staining}

The histologic material fixed in $10 \%$ formalin and embedded in paraffin was cut into $4 \mu \mathrm{m}$ slides and they were incubated for $12 \mathrm{~h}$ at $37^{\circ} \mathrm{C}$, dewaxed in a histological clearing agent, Histo-Clear (National Diagnostics, Atlanta, GA, USA), and hydrated. The specimens were treated with $0.4 \%$ pepsin (Sigma, St Louis, MO, USA) for $20 \mathrm{~min}$ at $37^{\circ} \mathrm{C}$. The avidin-biotin-immunoperoxidase technique was used according to $\mathrm{Hsu}$ et al, 1981. Mouse monoclonal antibody (CA-4001; Diabor Ltd, Oulu, Finland) against MMP-2 was used as a primary antibody. The antibody has been previously shown to detect the latent (inactive), $70-72 \mathrm{kDa}$ form of MMP-2. The specificity has been confirmed by a Western blot analysis (Höyhtyä et al, 1994). Endogenous peroxidase activity was blocked by incubating the slides in 3\% hydrogen peroxide in absolute methanol for $15 \mathrm{~min}$, and nonspecific binding was blocked with $10 \%$ goat serum for $15 \mathrm{~min}$.

The specimens were incubated for $60 \mathrm{~min}$ at room temperature in a humidity chamber, and immunohistological staining was continued using a Histostain-bulk kit (Zymed, San Francisco, CA, USA) according to the manufacturer's instructions. Biotinylated anti-mouse IgG served as a second antibody, and the peroxidase was introduced using a streptavidin conjugate. The slides were washed thoroughly with phosphate-buffered saline between each stage in the procedure. The antibody reaction was visualised using a fresh substrate solution containing an aminoethyl carbazole substrate kit (AEC, Sigma). The sections were counterstained with haematoxylin, dehydrated and mounted in glycerol-vinyl-alcohol (GVA mount, Zymed). For the negative controls, the primary antibody was replaced with mouse nonimmuno IgG. For the positive controls, we used previously known MMP-2-positive specimens of breast carcinoma.

\section{Evaluation of the MMP-2 immunostaining}

A section was considered negative or positive according to the absence or presence of positive staining of the neoplastic cells. The staining was scored as follows: no positive cells, less than $50 \%$ of the neoplastic cells staining positive (MMP- $2+$ ) and $>50 \%$ of the neoplastic cells positive (MMP-2 ++ ).

Immunostaining for MMP-2 was scored by three independent observers. Only cases giving repeatable scores in immunostaining were included in the data. The clinical data were collected and analysed after the evaluation of the immunostaining scores for a given case. The scoring of the immunoreaction and collecting the clinical data were performed independently without knowledge of each other.

\section{Statistical analysis}

The score for MMP-2 immunoreactivity was compared with other prognostic variables by the $\chi^{2}$ method. $P$-values $<0.05$ were considered statistically significant.

Survival was defined as the time elapsing from the primary operation to the date of death due to breast carcinoma. The recurrence-free survival (RFS) was determined as time in months from the date of diagnosis to the date of local recurrence or metastasis.

Survival rates were analysed by the Kaplan-Meier method (Kaplan and Meier, 1958) for up to 10 years of the follow-up. Differences between the subgroups were compared by means of a log-rank test (Mantel, 1966) for up to 10 years. The effect of MMP2 positivity on survival was analysed in various subgroups representing the major prognostic variables recognised in breast carcinoma.

The multivariate analysis was tested with the Cox's regression model of survival time (Cox, 1972). BMDP statistical software (University of California Press, Berkeley, CA, USA) was used (Dixon et al, 1990).

\section{RESULTS}

In this study, intracytoplasmic staining of the protein for MMP-2 was found in $78 \%$ of the primary tumours of breast carcinoma, $50 \%$ displaying an extensive positivity ( $>50 \%$ of the tumour cells positive; MMP- $2++$ ). Negative staining (MMP-2) was found in $22 \%$ of the primary tumours of breast carcinoma. The immunoreactive protein in carcinoma cells localised to the cytoplasm (Figure 1A, B). There was no correlation between the MMP-2 protein expression and stage, grade or hormone receptor status (Table 1).

A statistically significant correlation between MMP-2 positivity and overall survival was found in this study. The 10 -year overall survival was $72 \%$ in patients with an MMP-2 immunoreactive protein positive $(+)$ and $64 \%$ in patients with an MMP-2 immunoreactive protein strongly positive $(++)$ breast carcinoma, compared to $77 \%$ in the patient group with an MMP-2negative primary tumour, the 10 -year RFS being 60,56 and $64 \%$, respectively (Figure $2 \mathrm{~A}, \mathrm{~B}$ ).

In the node-negative patient group, all patients with MMP-2negative immunostaining were alive in the follow-up time of 10 years. In the patient group with a positive immunohistochemical staining for MMP-2, the overall survival was $87 \%(P=0.03$, Table 2).

Out of 334 breast carcinoma patients, 72 were negative for oestrogen receptors and 96 for progesterone receptors. In these patients, the MMP-2 positivity indicated a very unfavourable 


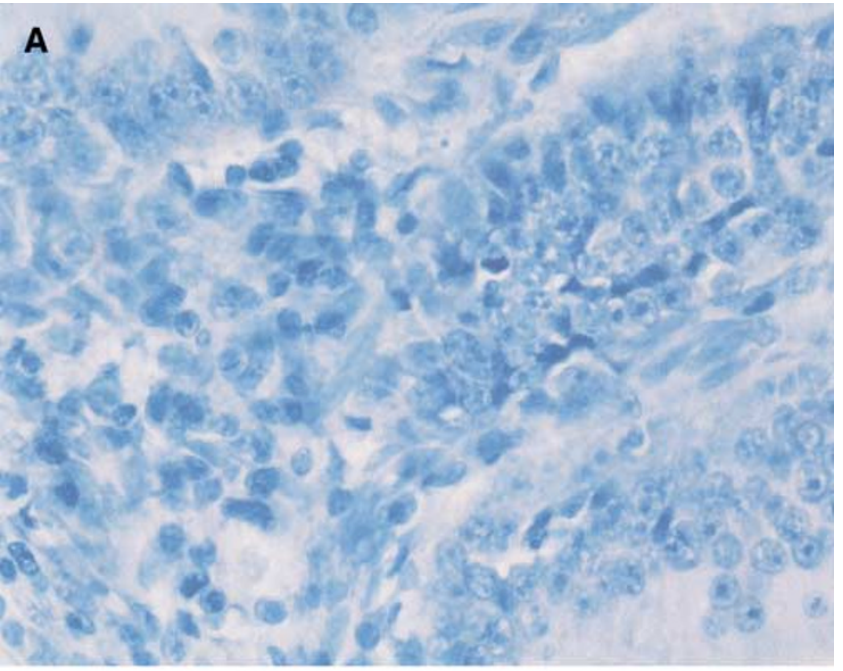

Table I Expression of MMP-2 immunoreactive protein in breast carcinoma

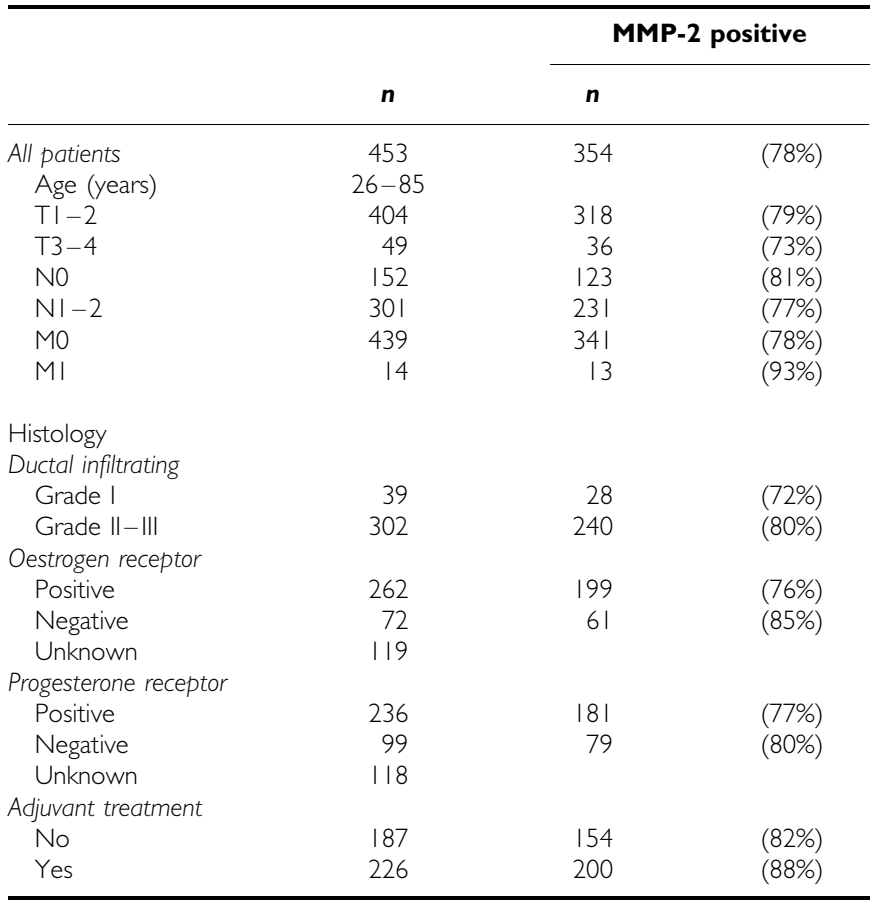

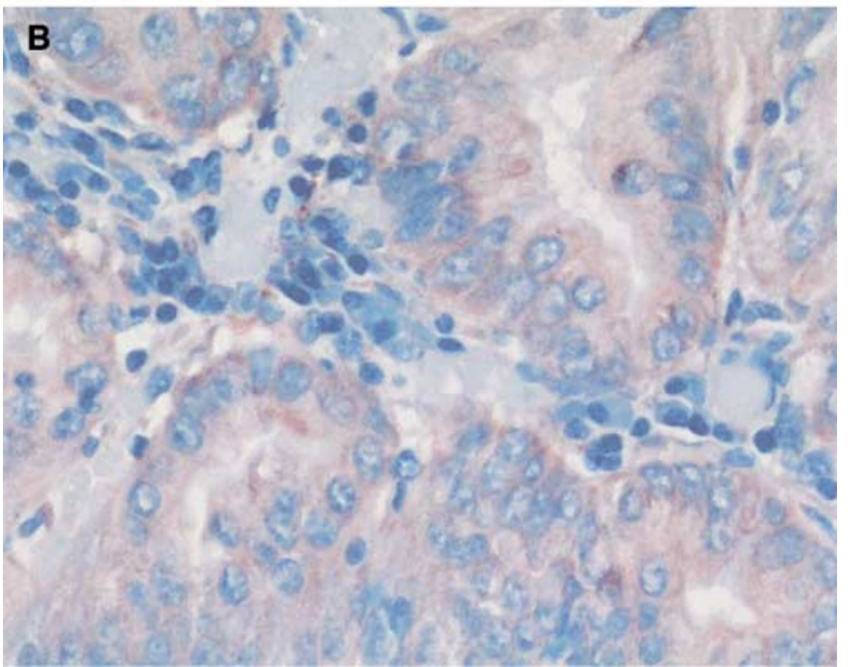

Figure I Cytoplasmic immunostaining of MMP-2 in primary breast carcinoma. Immunostaining was performed as described in Materials and Methods by using an anti-MMP-2 monoclonal antibody: $(\mathbf{A})$ negative $(-)$, (B) positive $(++)$ case.

prognosis. In all, 58\% of the patients presenting with MMP-2positive and oestrogen $(n=59)$ or progesterone $(n=96)$ receptornegative primary tumour were alive after the 10 years of follow-up. In contrast, $90 \%$ of the patients with an MMP-2-negative, oestrogen receptor-negative $(n=12)$ tumour and $95 \%$ of those with an MMP-2 negative, progesterone receptor-negative $(n=20)$ tumour were alive at that time (Figure 3A, B). The Kaplan-Meier analysis showed that the RFS was 90 or $80 \%$ in patients with an MMP-2-negative, oestrogen receptor-negative or progesterone receptor-negative primary tumour, respectively, while it was $56 \%$ in the MMP-2-positive tumours in both oestrogen- or progesterone receptor groups $(P=0.047,0.023)$.

In grade 2 and 3, tumours MMP-2 positivity correlated significantly with shortened overall survival $(P=0.04)$. The 10 year RFS of the patients with MMP-2-negative primary tumour was $57 \%$, whereas it was $48 \%$ in those patients with a tumour displaying MMP-2 positivity $(P=0.05)$, the overall survival being $64 \%$ vs $59 \%$, respectively.

A multivariate analysis was conducted to evaluate further whether the correlation between MMP-2 positivity and shortened survival could be related to the association of MMP-2 with other prognostic factors. The results showed that MMP-2 positivity in
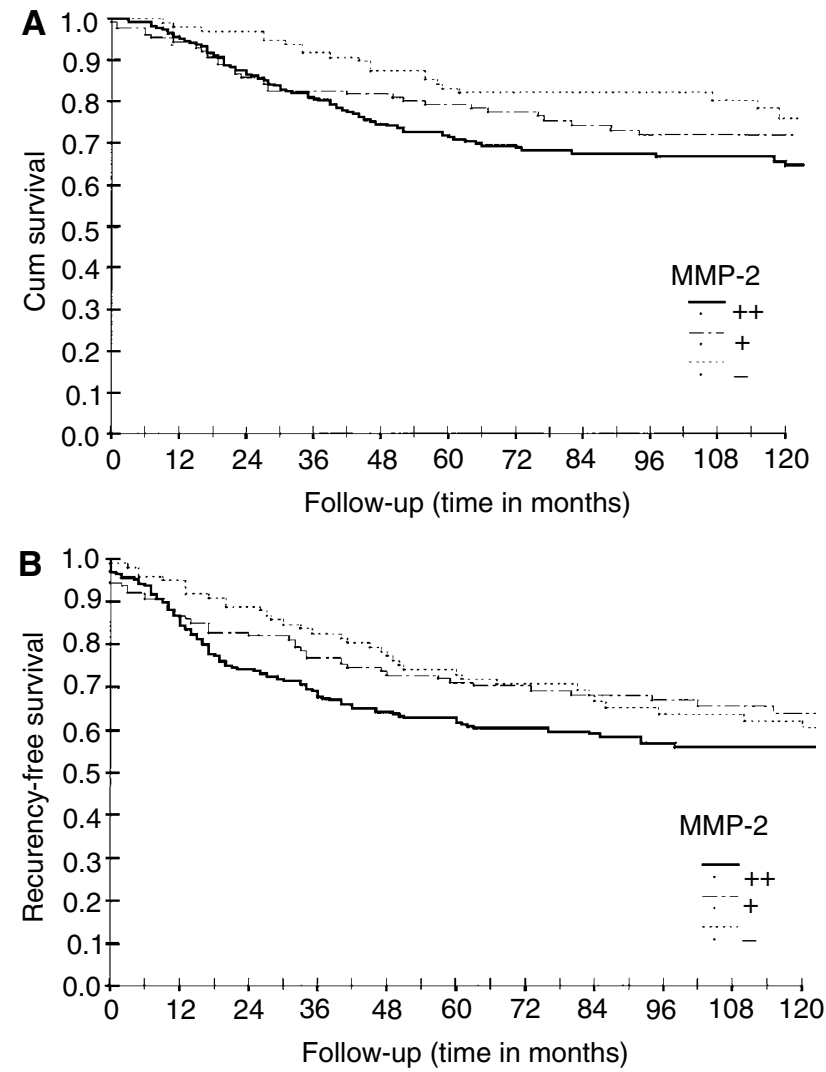

Figure 2 Survival analysis (Kaplan-Meier) of the breast carcinoma patients according to the MMP-2 immunoreactivity of the primary tumour (A) overall survival, (B) RFS. MMP-2 negative (-), MMP-2 positivity; weak $(+)$, strong $(++)$. Log-rank analysis of MMP-2 negative vs strong positive: (A) $P=0.03$, (B) $P=0.05$. 
Table 2 Recurrence-free and overall survival of breast carcinoma patients according to MMP-2 staining in different patient groups

\begin{tabular}{|c|c|c|c|c|}
\hline & \multicolumn{4}{|c|}{ MMP-2 immunoreaction } \\
\hline & \multicolumn{2}{|c|}{ Recurrence-free survival } & \multicolumn{2}{|c|}{ Overall surviva } \\
\hline & - & $+/++$ & - & $+/++$ \\
\hline All patients & 64 & 59 & 77 & $68 * * *$ \\
\hline $\mathrm{TI}-2$ & 66 & 60 & 80 & $70 * *$ \\
\hline Node negative & 79 & 78 & 100 & $87 * * * * *$ \\
\hline Node positive & 58 & $48 * * * * * *$ & 61 & 56 ******** \\
\hline \multicolumn{5}{|c|}{ Oestrogen receptor } \\
\hline Negative & 90 & 56 ******* & 90 & $58 * * * * * *$ \\
\hline Positive & 55 & 55 & 75 & $67 * *$ \\
\hline \multicolumn{5}{|c|}{ Progesterone receptor } \\
\hline Negative & 80 & $56 * *$ & 95 & $58 *$ \\
\hline Positive & 55 & 55 & 71 & 67 \\
\hline Grade II-III & 57 & $48 * * * * * *$ & 64 & $59 * * * *$ \\
\hline
\end{tabular}

$* P=0.005, * * P=0.02, * * * P=0.03$, ****** $P=0.04$, ****** $P<0.05$. The surviving fraction is given as \% at 10 years in Kaplan-Meier analysis.

carcinoma cells maintained its association with a poor outcome (Table 3). MMP-2 positivity appeared to increase the risk of death 1.8 -fold during the first 10 years of follow-up.

\section{DISCUSSION}

The expression of MMP-2 immunoreactive protein has been associated with invasive and metastatic tumours in previous in vitro studies (Liotta et al, 1980; Garbisa et al, 1987; Nakajima et al, 1987; Bernhard et al, 1990). In this study, intracytoplasmic expression of the protein for MMP-2 was found in $78 \%$ of the primary tumours of breast carcinoma. The amount of positive cases is in line with previously published data (Monteagudo et al, 1990; Daidone et al, 1991; Visscher et al, 1994; Talvensaari-Mattila et al, 1998, 1999, 2001; Lee et al, 1996). This study constitutes the largest material of breast carcinoma published showing the prognostic value of MMP-2.
A ER neg.

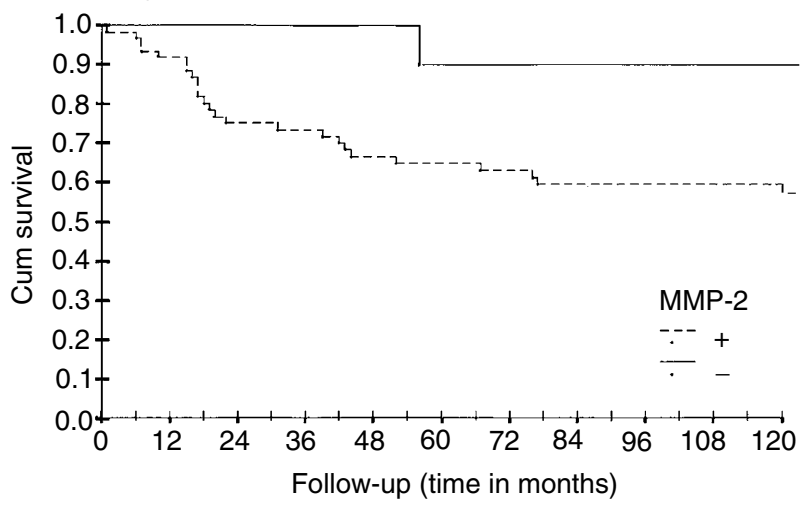

B PR neg.

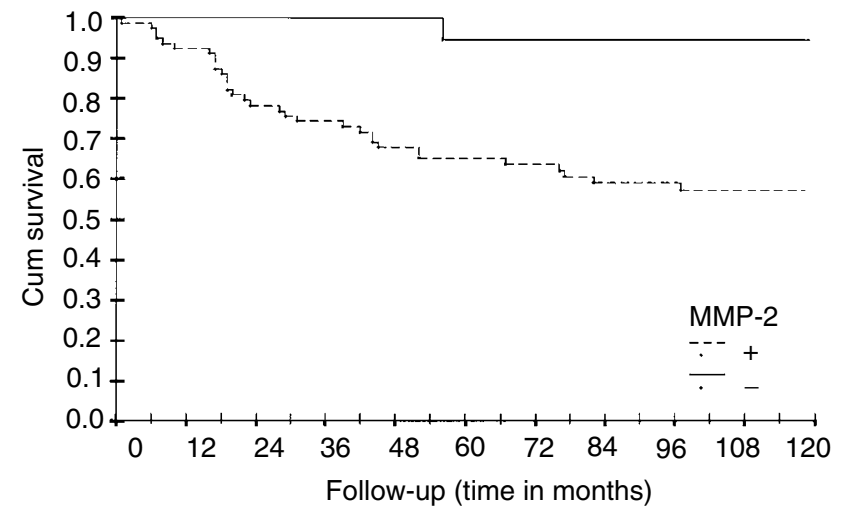

Figure 3 Relative survival of the breast carcinoma patients according to the MMP-2 immunoreactivity of the primary tumour in hormone receptornegative patient groups: (A) oestrogen receptor negative, (B) progesterone receptor negative patient groups. Log-rank analysis of MMP-2 negative vs positive. (A) $P=0.05$, (B) $P=0.005$

In this material consisting of 453 cases, the MMP-2 immunoreactive protein was able to predict a relapse during the 10 years of the follow-up. The 10 -year RFS was $60 \%$ in patients with a lowgrade $(+)$ and $56 \%$ in those with a strongly positive $(++)$

Table 3 Cox's regression model of survival time

\begin{tabular}{|c|c|c|c|c|c|c|c|}
\hline & $n=452$ & $\beta$ & s.e. & $P$ & OR & $95 \% \mathrm{Cl}$ for $\beta$ & OR's $P$-value \\
\hline MMP-2 & & & & 0.02 & & & \\
\hline Negative & 99 & & & & 1.00 & & \\
\hline Positive & 353 & 0.579 & 0.245 & & 1.78 & $1.10-2.88$ & 0.02 \\
\hline Age (years) & & & & 0.02 & & & \\
\hline$<55$ & 266 & & & & 1.00 & & \\
\hline$>55$ & 186 & 0.445 & 0.183 & & 1.56 & $1.09-2.23$ & 0.02 \\
\hline Tumour & & & & 0.001 & & & \\
\hline $1-2$ & 403 & & & & 1.00 & & \\
\hline $3-4$ & 49 & 1.106 & 0.223 & & 3.02 & $1.95-4.67$ & 0.001 \\
\hline Nodes & & & & 0.001 & & & \\
\hline 0 & 152 & & & & 1.00 & & \\
\hline $1-2$ & 300 & 1.375 & 0.285 & & 3.95 & $2.26-6.91$ & 0.001 \\
\hline Grade & & & & 0.01 & & & \\
\hline I & 39 & & & & 1.00 & & \\
\hline$\|-1\|$ & 302 & 1.923 & 0.715 & & 6.84 & $1.68-27.8$ & 0.01 \\
\hline
\end{tabular}

$\beta=$ coefficient; s.e. $=$ standard error of the mean; $\mathrm{OR}=$ odds ratio. 
tumour, compared to $64 \%$ in patients with an MMP-2-negative tumour. Also, the 10-year overall survival rate was significantly inferior among these patients. These differences are high enough to be also clinically significant, and especially the differences between - and ++ groups suggest that the MMP-2 immunoreactive protein is worthy of careful evaluation as a possible marker for biologic aggressiveness in breast carcinoma patients. Further, the previous studies have failed to show any statistically significant differences in survival between the patients with MMP-2-negative $v s$-positive primary tumours in node-negative patient group. Here the patient group presenting an MMP-2-negative primary breast carcinoma without a lymph node involvement enjoyed an excellent prognosis for survival, $100 \%$ of the patients being alive after 10 years of follow-up (Table 2). No difference was, however, found in the RFS suggesting that MMP-2 negativity may be associated with better responses to treatment of the metastatic disease and/or show progression of the disease.

The patients with an MMP-2-negative breast carcinoma form a relatively large patient group when the incidence of breast carcinoma is taken into consideration. It is possible that the lack of MMP-2 could become an important factor in certain subgroups of breast carcinoma when selecting the adjuvant therapy. A wellknown risk factor in breast carcinoma is hormone receptor negativity. It is interesting that $90 \%$ of the patients with an oestrogen receptor negative, MMP-2 negative or $95 \%$ of the patients with a progesterone receptor negative, MMP-2 negative primary tumour were alive after the 10 years of the follow-up (Figure $3 \mathrm{~A}, \mathrm{~B}$ ). On the contrary, only $58 \%$ of patients displaying MMP-2 positivity and oestrogen or progesterone receptor negativity were alive at that time. These differences were statistically highly significant, suggesting that these patient groups might need more attention in further studies. The patient group is small in percentages (about $4 \%$ of all breast carcinoma patients), but interesting both biologically and clinically. The number of those patients still exceeds the number of patients representing many more uncommon carcinoma types. The regulation of MMP-2 by female sex hormones may be an yet unknown mechanism which could explain this result. This conclusion indicates the need for further studies to explore the value of this enzyme in clinical decision-making.

In grade 2 and 3 tumours, MMP- 2 correlated significantly with shortened RFS and overall survival (Table 2). It is interesting to note that, MMP-2 negativity in this patient group was a strong marker for a favourable prognosis. Barozzi et al (2002) reported that TGF- $\alpha$, MMP-2 and IGF-II seem to be suitable candidates for a selective panel of markers designed to provide significant information with respect to the current pathologic staging system for patients with colorectal carcinoma.

In conclusion, we show here in a relatively large breast carcinoma patient group that MMP-2 immunoreactive protein is an independent prognostic indicator that might prove valuable in certain subgroups, such as patients with a receptor-negative breast carcinoma. The present data shows for the first time that MMP-2 negativity could serve as a marker for distinctly favourable prognosis in breast carcinoma patients. MMP-2 positivity is also shown to correlate to poor survival in node-negative breast carcinoma.

\section{ACKNOWLEDGEMENTS}

We thank Mr Ari Sarpola, MSc, for help with the statistical analyses. The study was supported in part by a grant from the $\mathrm{Oy}$ Eli Lilly Finland $\mathrm{Ab}$ and the Cancer Society of Northern Finland.

\section{REFERENCES}

Barozzi C, Ravaioli M, D’Errico A, Grazi GL, Poggioli G, Cavrini G, Mazziotti A, Grigioni WF (2002) Relevance of biologic markers in colorectal carcinoma: a comparative study of a board panel. Cancer 1: 647-657

Bernhard EJ, Muschel RJ, Hughes EN (1990) Gelatinase release correlates with the metastatic phenotype in transformed rat embryo cells. Cancer Res 50: $3872-3877$

Bloom HJG, Richardson WW (1957) Histological grading and prognosis in breast cancer. Br J Cancer 11: 359-377

Cox DR (1982) Statistical significance tests. Br J Clin Pharm 14: 325-331

Curran S, Murray GI (1999) Matrix metalloproteinases in tumour invasion and metastasis. J Pathol 189: $300-308$

Daidone MG, Silvestrini R, D'Errico A, Di Fronzo G, Benini E, Mancini WAM, Garbisa S, Liotta LA, Grigioni WF (1991) Laminin receptors, collagenase IV and prognosis in node-negative breast cancers. Int $J$ Cancer 48: $529-532$

Davidson B, Goldgerg I, Gotlieb WH, Kopolovic J, Ben-Baruch G, Nesland JM, Berner A, Bryne M, Reich R (1999) High levels of MMP-2, MMP-9, MT1-MMP and TIMP-2 mRNA correlate with poor survival in ovarian carcinoma. Clin Exp Metastasis 17: 799-808

Davies B, Miles DW, Happerfield LC, Naylor MS, Bobrow LG, Rubens RD, Balkwill FR (1993) Activity of type IV collagenases in benign and malignant breast disease. Br J Cancer 67: 1126-1133

D'Errico A, Garbisa S, Liotta LA, Castronovo R, Stetler-Stevenson W, Grigioni WF (1991) Augmentation of type IV collagenase and laminin receptors immunoreactivity associated with human breast, colon and gastric carcinoma progression. Mod Pathol 4: 239-246

Dixon WJ, Brown MB, Engelman L (1990) BMDP Statistical Software 1990. Berkeley: University of California Press

Ellenrieder V, Alber B, Lacher U, Hendler SF, Menke A, Boeck W, Wagner M, Wilda M, Friess H, Buchler M, Adler G, Gress TM (2000) Role of MT-MMPs and MMP-2 in pancreatic cancer progression. Int J Cancer 85: 14-20
Finnish Cancer Registry (1995) Cancer incidence in Finland 1995 (1997). Cancer Society of Finland, Helsinki

Garbett EA, Reed MW, Brown NJ (1999) Proteolysis in breast and colorectal cancer. Br J Cancer 8: 287-293

Garbett EA, Reed MW, Stephenson TJ, Brown NJ (2000) Proteolysis in human breast cancer. J Clin Pathol 53: 99-106

Garbisa S, Pozzati R, Muschel RJ, Staffiotti U, Ballin M, Goldfarb RH, Khoury G, Liotta LA (1987) Secretion of type IV collagenolytic protease and metastatic phenotype: induction by transfection with c-Ha-ras but not C-Ha-ras plus Ad2Ela. Cancer Res 47: 1523-1528

Giannelli G, Bergamini C, Marinosci F, Fransvea E, Quaranta M, Lupo L, Schiraldi O, Antonaci S (2002) Clinical role of MMP-2/TIMP-2 imbalance in hepatocellular carcinoma. Int J Cancer 97: 425-431

Hermanek P, Sobin LH (editors) (1992) UICC TNM Classification of Malignant Tumours, 4th edn, 2nd rev. Berlin: Springer-Verlag

Hsu SM, Raine L, Fanger H (1981) The use of avidin-biotin-peroxidase complex $(\mathrm{ABC})$ in immunoperoxidase technique: a comparison between $\mathrm{ABC}$ and unlabeled antibody (PAP) procedures. J Histochem Cytochem 29: $577-580$

Höyhtyä M, Fridman R, Komarck D, Porter-Jordan K, Stetler-Stevenson WG, Liotta LA, Liang CM (1994) Immunohistochemical localization of matrix metalloproteinase-2 and its specific inhibitor TIMP-2 in neoplastic tissue with monoclonal antibodies. Int J Cancer 54: 500-505

Iwata H, Kobayashi S, Iwase H, Masaoka A, Fujimoto N, Okada Y (1996) Production of matrix metalloproteinases and tissue inhibitors of metalloproteinases in human breast carcinomas. Jpn J Cancer Res 87: $602-611$

Jones JL, Glynn P, Walker RA (1999) Expression of MMP-2 and MMP-9, their inhibitors, and the activator MT1-MMP in primary breast carcinomas. J Pathol 189: $161-168$

Jäälinoja J, Herva R, Korpela M, Höyhtyä M, Turpeenniemi-Hujanen T (2000) Matrix metalloproteinase-2 (MMP-2) immunoreactive protein is 
associated with poor grade and survival in brain neoplasms. J Neurooncol 46: $81-90$

Kaplan EL, Meier P (1958) Nonparametric estimation from incomplete observations. J Am Stat Assoc 53: $457-481$

Kodate M, Kasai T, Hashimoto H, Yasumoto K, Iwata Y, Manabe H (1997) Expression of MMP (gelatinase) in T1 adenocarcinoma of the lung. Pathol Int 47: 461-469

Lee KS, Rha SY, Kim SJ, Roh JK, Kim BS, Chung HC (1996) Sequential activation and production of matrix metalloproteinase-2 during breast cancer progression. Clin Exp Metastasis 14: 512-519

Levy AT, Cioce V, Sobel ME, Garbisa S, Grigioni WF, Liotta LA, StetlerStevenson WG (1991) Increased expression of the $72 \mathrm{kDa}$ type IV collagenase in human colonic adenocarcinoma. Cancer Res 51: $439-444$

Liotta LA, Stetler-Stevenson WG (1990) Metalloproteinases and cancer invasion. Semin Cancer Biol 1: $99-106$

Liotta LA, Tryggvason K, Garbisa S, Hart I, Foltz CM, Shafie S (1980) Metastatic potential correlates with enzymatic degradation of basement membrane collagen. Nature 284: $67-68$

Liotta LA, Wewer U, Rao NC, Schiffmann E, Stracke M, Guirguis R, Thorgeirsson U, Muschel R, Sobel M (1998) Biochemical mechanisms of tumor invasion and metastases. Prog Clin Biol Res 256: 3-16

Mantel N (1966) Evaluation of survival data and two new rank order statistics arising in this consideration. Cancer Chemother Rep 50: $163-170$

Monteagudo C, Merino MJ, San-Juan J, Liotta LA, Stetler-Stevenson WG (1990) Immunohistochemical distribution of type IV collagenase in normal, benign, and malignant breast tissue. Am J Pathol 136: 585-592

Nakajima M, Welch DR, Belloni PN, Nicolson GL (1987) Degradation of basement membrane type IV collagen and lung subendothelial matrix by rat mammary adenocarcinoma cell clones of differing metastatic potentials. Cancer Res 47: 4869-4876
Parkin D, Whelan S, Gao Y, Ferley J, Raymond L, Young J (1997) Cancer Incidence in Five Continents, Vol 7, No 143, Lyon, France: IARC Scientific Publication

Sakata K, Shigemasa K, Nagai N, Ohama K (2000) Expression of matrix metalloproteinases (MMP-2, MMP-9, MT1-MMP) and their inhibitors (TIMP-1, TIMP-2) in common epithelial tumors of the ovary. Int J Oncol 17: $673-681$

Scarff RW, Torloni H (1986) Histological Typing of Breast Tumours. Geneva: WHO

Talvensaari-Mattila A, Pääkkö P, Blanco-Sequeiros G, TurpeenniemiHujanen T (2001) Matrix metalloproteinase-2 (MMP-2) is associated with the risk for a relapse in postmenopausal patients with node-positive breast carcinoma treated with antiestrogen therapy. Breast Cancer Res Treat 65: $55-56$

Talvensaari-Mattila A, Pääkkö P, Höyhtyä M, Blanco-Sequeiros G, Turpeenniemi-Hujanen T (1998) Matrix metalloproteinase-2 immunoreactive protein, a marker of aggressiveness in breast carcinoma. Cancer 83: $1153-1162$

Talvensaari-Mattila A, Pääkkö P, Turpeenniemi-Hujanen T (1999) MMP-2 positivity and age less than 40 years increases the risk for recurrence in premenopausal patients with node-positive breast carcinoma. Breast Cancer Res Treat 58: $287-293$

Tryggvason K, Höyhtyä M, Pyke C (1993) Type IV collagenase in invasive tumors. Breast Cancer Res Treat 24: 209-218

Visscher DW, Höyhtyä M, Ottosen SK, Liang C-M, Sarkar FH, Crissman D, Fridman R (1994) Enhanced expression of tissue inhibitor of metalloproteinase-2 (TIMP-2) in the stroma of breast carcinomas correlates with tumor recurrence. Int J Cancer 59: 339-344

Väisänen A, Kallioinen M, Taskinen PJ, Turpeenniemi-Hujanen T (1998) Prognostic value of MMP-2 immunoreactive protein $(72 \mathrm{kD}$ type IV collagenase) in primary skin melanoma. J Pathol 186: $51-58$ 